\title{
Histomorphometric analysis of inflammatory response and necrosis in re-implanted central incisor of rats treated with low-level laser therapy
}

\author{
Rianne Gomes Vilela • Kjersti Gjerde • Lucio Frigo • \\ Ernesto Cesar Pinto Leal Junior • Rodrigo Álvaro Brandão Lopes-Martins • \\ Brígida Mônica Kleine • Igor Prokopowitsch
}

Received: 17 February 2011 /Accepted: 9 May 2011 /Published online: 27 May 2011

(C) The Author(s) 2011. This article is published with open access at Springerlink.com

\begin{abstract}
Low-level laser therapy is a tool employed in the management of post-operative inflammation process and in the enhancement of reparative process. The aim of the study was to perform histological evaluation of dental and periodontal ligament of rats central upper-left incisor teeth re-implanted and irradiated with low-level laser (InGaAl, $685 \mathrm{~nm}, 50 \mathrm{~J} / \mathrm{cm}^{2}$ ) 15, 30, and 60 days after reimplantation. Seventy-two male rats had the central upper left incisor removed and kept for 15 min on dry gauze
\end{abstract}

R. G. Vilela $\cdot$ L. Frigo $\cdot$ I. Prokopowitsch

School of Dentistry, Cruzeiro do Sul University (UNICSUL),

São Paulo, Brazil

K. Gjerde

Department of Clinical Dentistry, Faculty

of Medicine and Dentistry, University of Bergen,

Bergen, Norway

E. C. P. Leal Junior $(\bowtie) \cdot$ R. Á. B. Lopes-Martins

Post Graduate Program in Rehabilitation Sciences,

Nove de Julho University (UNINOVE),

Rua Vergueiro, 235,

01504-001 São Paulo, SP, Brazil

e-mail: ernesto.leal.junior@gmail.com

R. Á. B. Lopes-Martins

Laboratory of Pharmacology and Experimental Therapeutics,

University of São Paulo (USP),

São Paulo, Brazil

B. M. Kleine

Certificate Program of Endodontics, APCD SCS,

São Paulo, Brazil

I. Prokopowitsch

Department of Endodontics School of Dentistry,

University of São Paulo,

São Paulo, Brazil before replantation. Laser was irradiated over the root surface and empty alveolus prior replantation and over surrounding mucosa after the re-implantation. After histological procedures, all slices were analyzed regarding external resorption area and histological aspects. We observed an increase of root resorption $(p<0.05)$ in the control group compared to the laser group at 15, 30, and 60 days. These results showed that the laser groups developed less root resorption areas than the control group in all experimental periods. Additionally, histological analysis revealed less inflammatory cells and necrotic areas in laser groups.

Keywords Avulsion · Re-implant · LLLT · Inflammation · Root resorption $\cdot$ Histological analysis

\section{Introduction}

A growing number of people fall victim to several kinds of oral-facial accidents on a daily basis. The resulting trauma affects not only the mouth but also the teeth, and may lead to an irreversible damage in its supporting apparatus. Dental trauma occurs more often in childhood and the upper central incisors are usually the most affected teeth [1, 2]. Dental avulsions are probably the situation that has the highest complexity to manage among several clinical situations of traumatized teeth [3,4]. Sometimes it is not possible to re-implant the tooth immediately, so the treatment has to take into account the time that tooth spent out of the alveolus, its pre-reimplantation milieu of storage, such as, salt solution, coconut water, milk, saliva, calcitonin and alendronate that changes the periodontal ligament dehydration degree prior re-implantation, as well as the root development degree [5-10]. These aspects change 
the prognosis of the re-implanted teeth in the attempt to avoid root resorption, as well as the patient's age [8, 11-13] and the post-reimplantation containment $[6,11,14]$.

External root resorption is radiographically characterized by the removal of the root dentine tissue, with or without a radiolucid image, which has different aspects and location as lateral gaps, rounding the apex or even a heavy progressive loss of dental tissue. The injured supporting tissue undergoes an inflammatory response to remove the damaged tissue prior to the start of the reparative process. The main feature of the inflammatory process is the intense osteoclastic activity [4]. Therefore, the modulation of inflammatory process is important to attenuate external root resorption. With these aspects in mind, low-level laser therapy (LLLT) could be an important non-pharmacological tool due its modulatory properties in biological tissues.

Anti-inflammatory properties of LLLT are based on its effects in the reduction of prostaglandin $\mathrm{E}_{2}$, tumor necrosis factor- $\alpha$, interleukin- $1 \beta$, ciclooxigenase- 2 mRNA, and plasminogen activator levels [15].

At the cellular level, biomodulation occurs through the increase of the ATP production due to a change in the redox properties of the carriers in the respiratory chain following photoexcitation of their electronic states and acceleration of electron transfer (primary reactions). Secondary reactions occur by increasing cell membrane transporters $\left(\mathrm{Na}^{+} / \mathrm{H}^{+}\right.$ antiporter, $\mathrm{Na}^{+} / \mathrm{K}^{+}$ATPase), concentration of second messengers $\left(\mathrm{Ca}^{2+}, \mathrm{cAMP}\right)$ and synthesis of DNA and RNA 27 [16]. Providing a rise in mitotic velocity and protein synthesis thus leads to quick tissue regeneration [17-19]. Laser therapy also has other effects on tissues, such as increasing blood flow and lymphatic drainage, and the activation of the immune and microcirculation systems [1721]. Due the reduction in the inflammatory process, LLLT has, as a secondary effect, an analgesic action [15]. LLLT in endodontics has proven to be as effective as intracanal medication in the post-operative pain and offers a less sensitive post-operative period when applied immediately following emergency therapy [22].

In this perspective, the aim of our study was to evaluate the histological conditions of the dental and periodontal ligaments in the central upper-left incisor teeth in rats reimplanted with (and without) low-level laser irradiation (at 15, 30, and 60 days after re-implantation).

\section{Materials and methods}

\section{Animals}

All experiments were performed with the approval of and in accordance with the regulations laid down by UNICSUL Bioethical Committee.
Seventy-two male adult Wistar rats (180-200 g) were housed under standard conditions of temperature $\left(22-25^{\circ} \mathrm{C}\right)$, relative humidity $(40-60 \%)$, and light/dark cycle $(12 / 12 \mathrm{~h})$ with access to food and water ad libitum.

\section{Experimental procedures}

The animals were weighed and sedated with ethylic ether and then received an intramuscular injection of xylazine chloride (Rompum; Bayer of Brazil, São Paulo, SP Brazil; $0.2 \mathrm{cc} / 100 \mathrm{~g}$ body weight) to attain muscular relaxation and they were anesthetized intramuscularly with Ketamine chloride (Ketalar; Parke-Davis, Aché Laboratories, São Paulo, SP, Brazil; $0.2 \mathrm{cc} / 100 \mathrm{~g}$ body weight).

After shaving and asepsis of the mandible, the central upper left incisor was removed from each rat using specially adapted forceps. The tooth was kept for $15 \mathrm{~min}$ on dry gauze. Therefore, damage was caused to the periodontal membrane, which induces, after the reimplant, rates of external root resorption depending on the experimental time period. Thereafter, the rats were randomly assigned to two groups $(n=36)$ according to the treatment given: G1 (control) = teeth were stored for 15 min on dry gauze post-extraction and drooped in saline solution prior re-implantation and re-implanted without laser treatment; G2 (laser) = teeth were stored for $15 \mathrm{~min}$ on dry gauze post-extraction and drooped in saline solution and low-level laser irradiation was applied prior reimplantation. The laser application was carried out on the alveolus interior and on the root surface in a sweeping manner. After re-implanting, another laser irradiation was carried out on the entrance and lingual face of the alveolar edge. In this manner, four irradiations of $50 \mathrm{~J} / \mathrm{cm}^{2}$ were performed.

After re-implantation, the teeth were replaced with a slow and delicate movement using forceps and before containment it was performed the process of reduction in bone tissue dislocation. The figure-of-eight containment was made by bracing the re-implanted tooth and the central upper right incisor with silk suture thread - Med Suture - 3/ $0-$ ST -04 . Subsequently, acid conditioning of the enamel on the vestibular surface of the re-implanted tooth crown and containment with composite resin was performed using phosphoric acid for 2 min followed by washing with distilled water and drying with cotton. First, the prime and bond was applied and polymerized, and then we applied a small amount of composite resin from $\left(\mathrm{Z} 1003 \mathrm{M}^{\mathbb{}}\right)$, in such a manner that the crenels were resin-free, thus providing semi-rigid containment. After this, an intramuscular antibiotic application was performed using benzathine benzylpenicillin (20,000 IU) in the posterior left paw. 


\section{Laser parameters}

A continuous-wave diode laser (InGaAlP) (Quasar Medical, Dentoflex, Brazil) with an output power of $50 \mathrm{~mW}$ and a wavelength of $685 \mathrm{~nm}$ was used. The spot size was $0.02 \mathrm{~cm}^{2}$ and the optical power density was $2.5 \mathrm{~W} / \mathrm{cm}^{2}$. The optical power was calibrated using a Newport Multifunction Optical Meter model 1835C. Laser irradiation dose was fixed at $50 \mathrm{~J} / \mathrm{cm}^{2}$ in four different points a total of $200 \mathrm{~J} / \mathrm{cm}^{2}$ in only one session. The tip was kept $1 \mathrm{~mm}$ from the irradiated tissue and total energy delivery was $1 \mathrm{~J}$ per point ( $4 \mathrm{~J}$ of total dose). The protocol of irradiation was the same for all experimental sub-groups.

\section{Euthanasia and histological method}

Twelve rats per group were killed by anesthetic overdose at each of the pre-determined evaluation periods at 15,30 , and 60 postoperative days. Teeth were removed in blocks encapsulating the re-implanted teeth tissues and its adjacent tooth duly labeled. Pieces were fixed in buffered formalin (4\%) for 24 $\mathrm{h}$ and dried in $70 \%$ alcohol for $24 \mathrm{~h}, 80$ and $90 \%$ alcohol for 1 $\mathrm{h}$ each, decalcified in Morse solution for 4 days, and thereafter submitted to routine laboratory processing. The specimens were embedded in paraffin and $6 \mu \mathrm{m}$-thick sectioned in a transverse plane of the root. Sections were stained with hematoxylin and eosin (H\&E) for histomorphological analysis.

\section{Morphological analysis}

Histomorphological analysis was performed by reading the areas of root resorption. These readings were taken by means of a computer program Imagelab ${ }^{\circledR} 2.3$ (LIDO, FOUSP, São Paulo, Brazil). These images allowed estimating the total tooth area and calculating the tooth area with external root resorption for 15-, 30-, and 60-day periods (Fig. 1a and b). These values were duly tabulated and the results were analyzed statistically with ANOVA and Tukey test, after all groups' data had normality accepted by Kolmogorov-Smirnov test. BioEstat 4.0 statistical software package 20 [23] was used and the significance level was set at $\alpha=5 \%$. To measure the root resorption percentage, the data was organized and analyzed based on the following formula: total area of tooth resorption times to 100 and divided by the total tooth area.

$\frac{\text { Total area of resorption } \times 100}{\text { Total tooth area }}=$ Resorption $\%$

Histological analysis

The histological analysis was performed under light microscopy (Nikon Eclipse E800) in 40, 200, and 400×
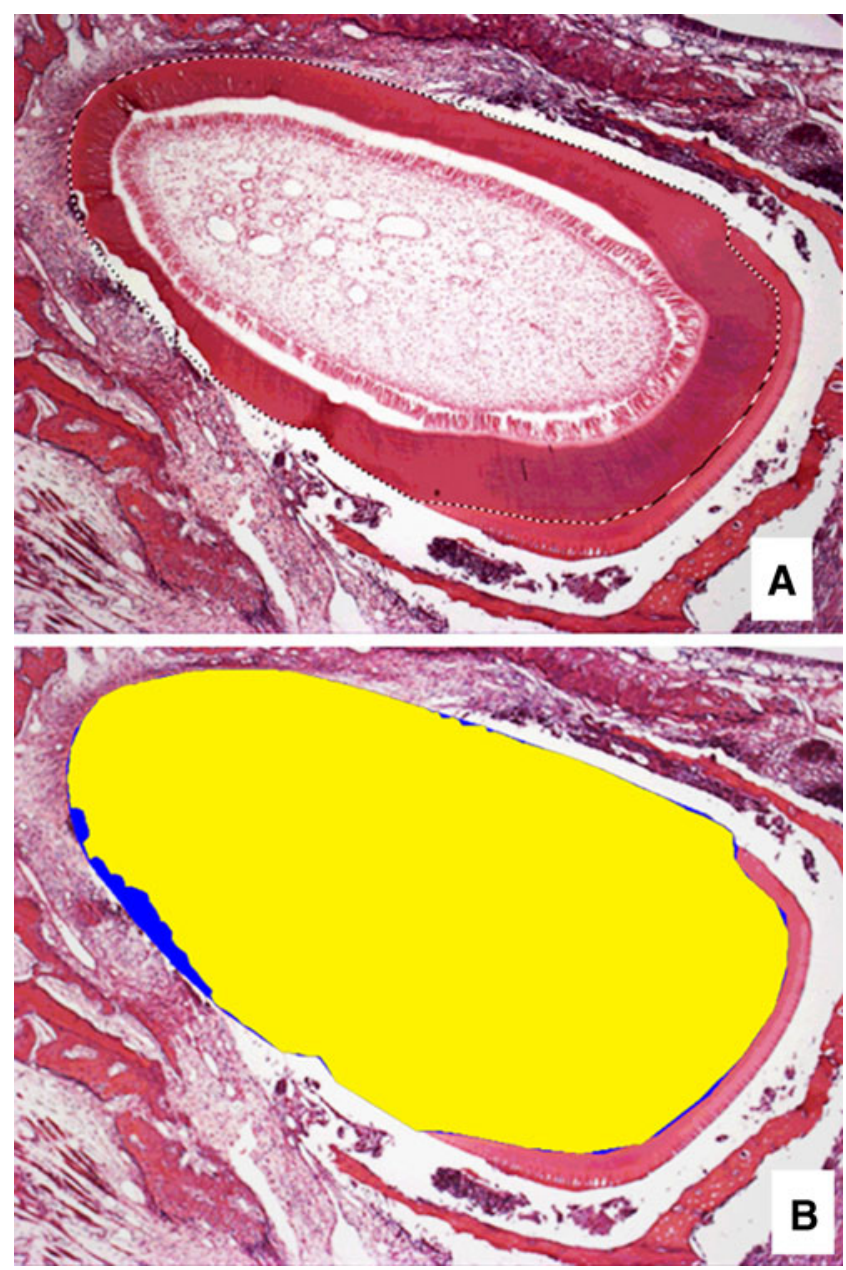

Fig. 1 a Morphologic analysis of samples. The dotted line around the root estimates the total root area. b Image processing by Imagelab 2.3 software, dividing the resorbed area (in blue) and remaining root area (yellow)

magnifications, depending on the observed structure. Four trained examiners blinded to the treatment of each group independently examined each section. In case of disagreement, the specimen was re-evaluated and a consensus was reached between the examiners. Evaluation was done in the cervical middle of the root because rat incisors are continuously growing teeth. The degree of inflammation in pulp and periodontal tissue was evaluated using the criteria below (Table 1).

\section{Results}

Morphological analysis

The presence of root resorption was observed in both groups (Fig. 1a and b). An increase of root resorption could be noted in both groups in longer experimental periods. Regarding quantitative evaluation, both groups had statistical significant differences $(p<0.05)$ between 15-, 30-, and 
Table 1 Scoring system used for light microscopic analyses

\begin{tabular}{|c|c|c|c|}
\hline \multirow[t]{2}{*}{ Inflammatory cells } & Slight & Moderate & Intense \\
\hline & $\begin{array}{l}\text { Presence of }<20 \% \text { of inflammatory } \\
\text { cells in the section }\end{array}$ & $\begin{array}{l}\text { Presence of } 20-40 \% \text { of inflammatory } \\
\text { cells in the section }\end{array}$ & $\begin{array}{l}\text { Presence of }>40 \% \text { of inflammatory } \\
\text { cells in the section }\end{array}$ \\
\hline \multirow{2}{*}{$\begin{array}{l}\text { Disorganization of } \\
\text { odontoblasts cell layer } \\
\text { and degenerating } \\
\text { odontoblasts }\end{array}$} & Slight & Moderate & Intense \\
\hline & $\begin{array}{l}\text { Presence of }<20 \% \text { of disorganization } \\
\text { of odontoblasts cell layer and } \\
\text { degenerating odontoblasts }\end{array}$ & $\begin{array}{l}\text { Presence of } 20-40 \% \text { of disorganization } \\
\text { of odontoblasts cell layer and } \\
\text { degenerating odontoblasts }\end{array}$ & $\begin{array}{l}\text { Presence of }>40 \% \text { of disorganization } \\
\text { of odontoblasts cell layer and } \\
\text { degenerating odontoblasts }\end{array}$ \\
\hline \multirow{2}{*}{ Necrotic areas } & Slight & Moderate & Intense \\
\hline & $\begin{array}{l}\text { Presence of }<20 \% \text { of necrotic areas in } \\
\text { the pulp }\end{array}$ & $\begin{array}{l}\text { Presence of } 20-40 \% \text { of necrotic areas } \\
\text { in the pulp }\end{array}$ & $\begin{array}{l}\text { Presence of }>40 \% \text { of necrotic areas } \\
\text { in the pulp }\end{array}$ \\
\hline
\end{tabular}

60-day periods. When G1 and G2 are compared in each experimental period, it is possible to observe significant differences in all comparisons $(p<0.01)$ (Table 2). Figure 2 shows areas used to make Figs. 3 and 4.

After 15 days of re-implantation, the LLLT and control group presented degenerating changes probably in consequence of the loss of the blood flow due to the dental avulsion. The periodontal ligament collagen fibers were broken, but inflammatory cells and blood clot were present.

The highest difference between the control group and the LLLT group was observed in the root pulp. Irradiated tooth odontoblasts presented slight degenerative morphological changes, so the cell layer was organized and cytoplasms were normally stained with their nucleuses present and were well preserved. On the other hand, intense degenerations were observed in the control group. Root pulp odontoblasts were disorganized, cytoplasms were pale, and nucleuses were not present or discolored, showing morphological evidence of degeneration (Fig. 3).

After 30 days of replantation, both groups developed pulpal and periodontal necrosis with the presence of dentinal resorption. In some areas, total loss of dentin allowed the pulp to become in close contact with the periodontal ligament.

However, differences between the control and the LLLT group were observed. The most evident difference was the number of pulpal inflammatory cells, scored as intense in control group as well as amounts of necrotic areas were scored as moderate. On the other hand, the LLLT group was scored slight for both parameters mentioned above (Fig. 4a, b).
After 60 days of re-implantation, both groups developed pulpal and periodontal necrosis with the presence of dentinal resorption and allowing the pulp to become in close contact with the periodontal ligament.

However, differences between the control and LLLT groups were observed. Necrosis and inflammatory cells were scored as moderate in LLLT group. Necrosis presented well-defined characteristics of liquefying necrosis with regional collection of eosinophilic material surrounded by inflammatory cells.

On the other hand, the control group was scored as intense for necrosis and inflammatory cells. The pulp presented necrosis in all extension with the following characteristics: greater number of inflammatory cells even in the pulp than in the periodontal ligament. Necrosis areas were also larger and presented basophilic material collection (Fig. 4c, d).

Additionally, every tooth rendered 25-30 transversal sections of the root cervical segment. A random 1 in 5 section was selected for analysis, a total of 5-6 sections per tooth. No tooth loss was observed, once the reimplanted incisor was attached to the neighbor tooth. However, severe inflammation could be inferred in two animals of the control group due to mucosae abscess observation.

\section{Discussion}

The present study was conducted in order to determine the role of LLLT in modulation of inflammatory process in

Table 2 Percentage of root resorption (\%) and standard deviations

\begin{tabular}{llll}
\hline & 15 days & 30 days & 60 days \\
\hline Control group $(\mathrm{G} 1)$ & $1.302 \pm 0.4348$ & $7.762 \pm 0.7828$ & $14.550 \pm 1.6971$ \\
Laser group $(\mathrm{G} 2)$ & $0.308 \pm 0.1645$ & $4.695 \pm 0.6929$ & $9.262 \pm 1.7680$ \\
Comparison of G1 $\times \mathrm{G} 2$ & $p<0.01$ & $p<0.01$ & $p<0.01$ \\
\hline
\end{tabular}




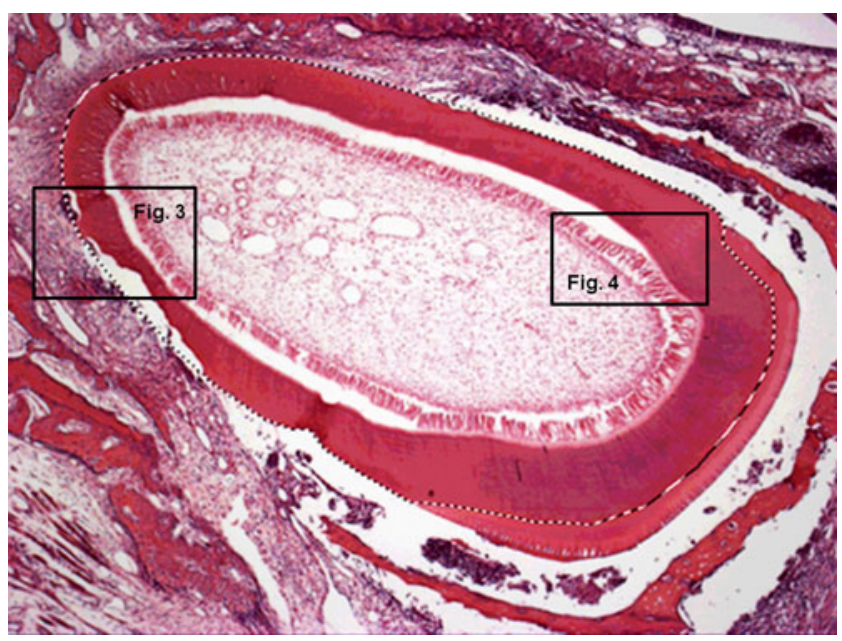

Fig. 2 Areas analyzed in Figs. 3 and 4

intentionally avulsed teeth of rats after storage for $15 \mathrm{~min}$ on dry gauze post-extraction and dropped in salt solution prior re-implantation.

Our results corroborate with those of Friedman et al. [22] who tested changes in root surface with $\mathrm{Nd}$ :YAG laser irradiation in dog premolars. In groups 1 and 2, premolars were inoculated with bacterial plaque and in groups 3 and 4 , endodontic treatment was administered without inoculation. In groups 1 and 3, extraction was carried out after 2 weeks, root surface was irradiated with Nd:YAG laser, and the tooth was re-implanted. In groups 1 and 2, inflammatory resorption was frequently present, and in groups 3 and 4 was absent, while regarding resorption by substitution was more present in groups 3 and 4 than in groups 1 and 2.

Our results are also in agreement with those of Merli et al. [21] who analyzed the effect of low-intensity laser irradiation in culture of rats' bone cells. They found that laser use probably increased bone formation through the stimulation of cell proliferation, particularly of the osteoblastic lineage and stimulation of cell differentiation. However, these effects were only observed in immature cells $[18,22]$.

Regarding the fact that there was significant statistical difference when the same experimental periods were compared (G1 × G2), it could be concluded that besides the analgesic and biostimulatory action of therapeutic laser,
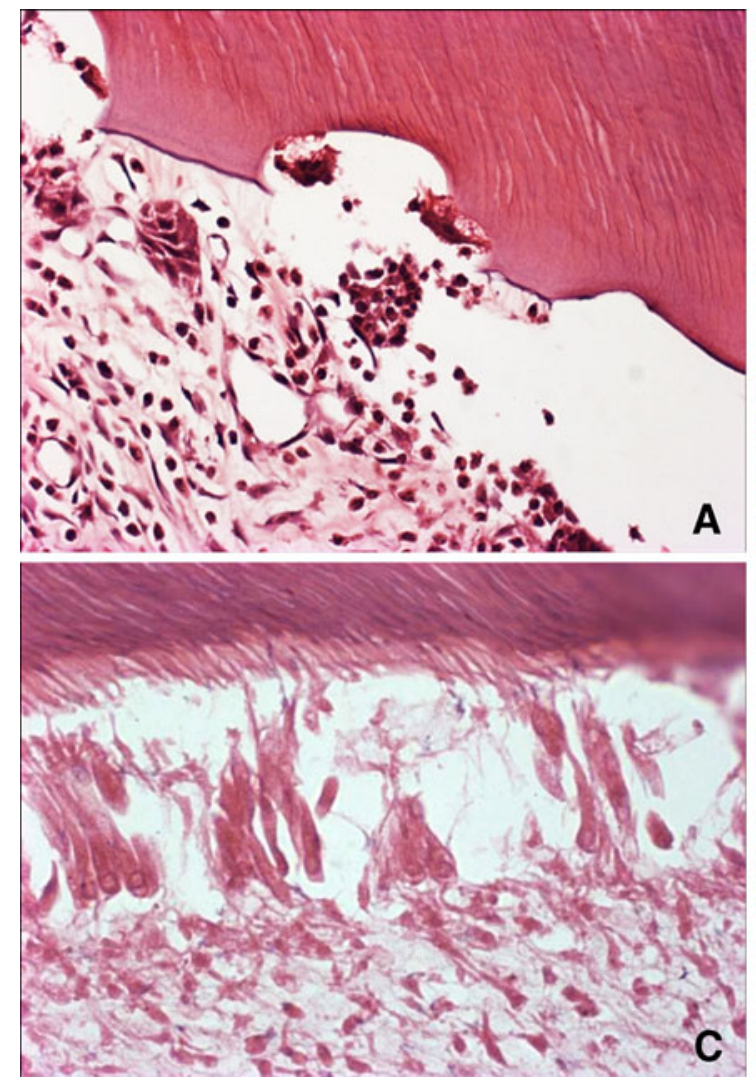

Fig. 3 a, b Transversal section of the cervical third root in the $15^{\text {th }}$ day. It was observed a region of external root resorption of the replanted root and the resorption responsible cells, the odontoclasts $(400 \times)$. c Root pulp histological section of the control group showing the odontoblastic layer with evidence of cell degeneration (cell
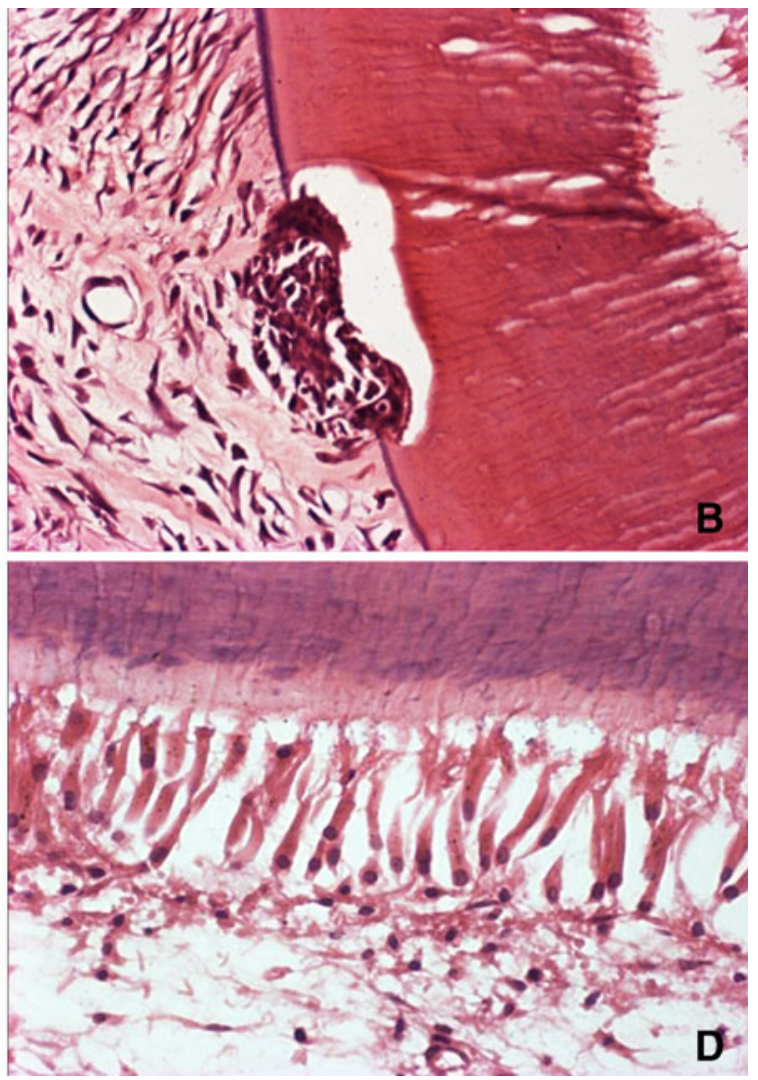

disorganization, nuclei and discolored cytoplasm, 15 days postreplant). d Root pulp histological section of the irradiated group showing the odontoblastic layer free of degenerative morphological alterations 15 days after implant $(400 \times)$ 

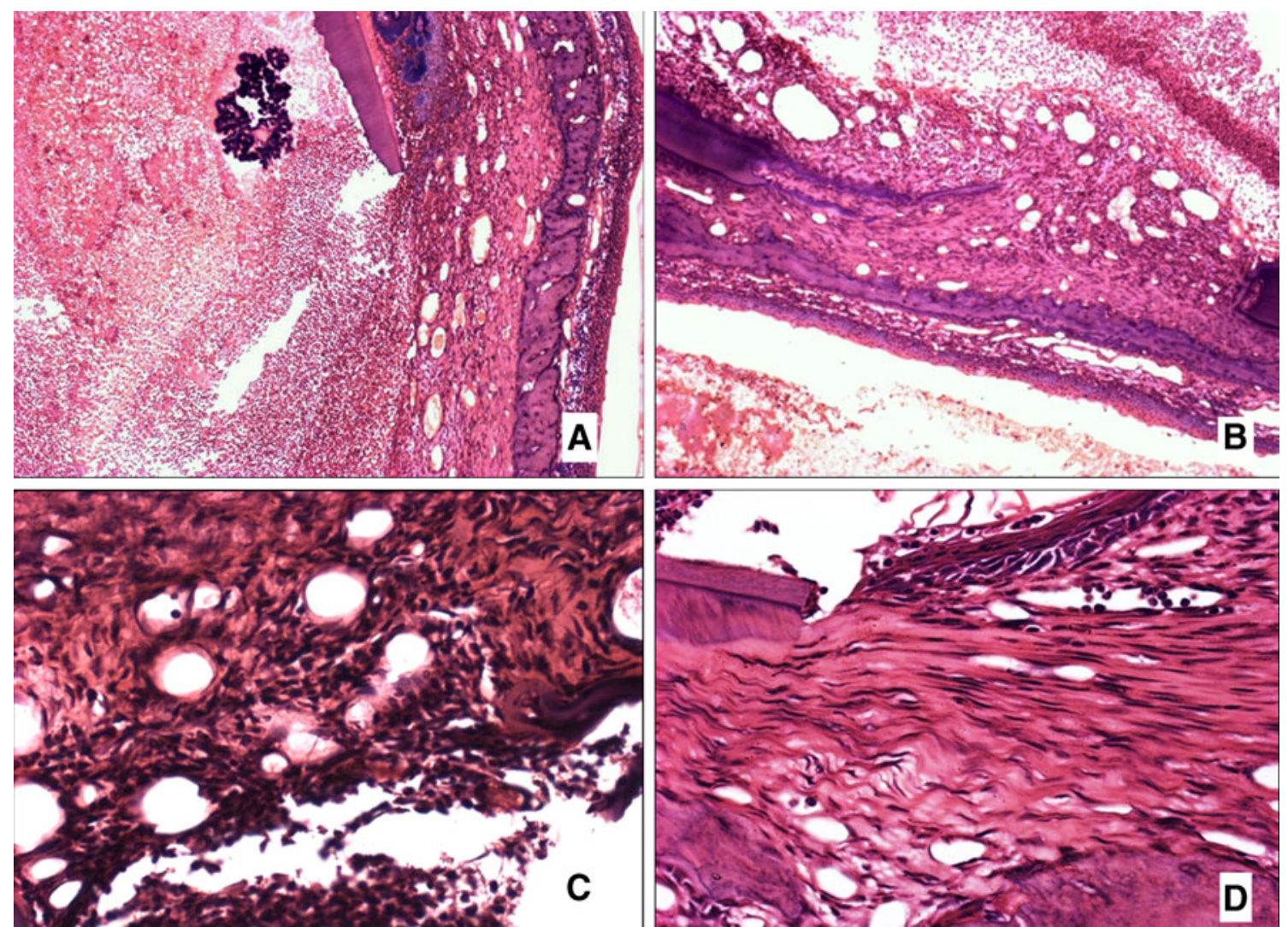

Fig. 4 a Root pulp histological section photomicrograph of the control group showing an intense inflammatory infiltration and regions of necrosis-affected tissue 30 days after replant $(100 \times)$. b Root pulp histological section photomicrograph of the irradiated group showing less inflammatory infiltration in comparison to the control group and an absence of necrosis-affected areas 30 days after replant. $(100 \times)$. c Periodontal histological section photomicrograph of the

which are desirable in cases of dental replantation, the antiinflammatory effect should help slow down the resorption process.

The comparative histological analysis between the 15day control and LLLT sub-group showed that in both groups, degenerative changes were present due to insufficient blood supply. However, the most important difference between the groups was observed in the pulpal tissue, where odontoblasts of the irradiated tooth did not show any degenerative morphological change, different than was observed in the control group. These findings can be explained by previous effects observed by Ferreira et al. [23] who noted that laser therapy could render odontoblasts with more capacity to react to environmental challenges.

The comparative histological analysis between 30-day control and LLLT sub-groups showed that in both groups pulpal and periodontal ligament necrosis was observed. However, the most important difference between the groups was seen by the quantity of the pulpal inflammatory cells control group showing intense inflammatory infiltration and total disorganization of collagen fibers 60 days after implant $(400 \times)$. d Periodontal histological section photomicrograph of the irradiated group showing a notable organization of the periodontal ligament fibers in addition to a discreet inflammatory infiltration 60 days postimplant $(400 \times)$

and necrosis areas that were more evident in the control group than in the irradiated group.

Expressive research data indicates that laser therapy is a consistent anti-inflammatory tool. It can modulate cell influx, hemorrhagic formation, inflammatory metabolites $\left(\mathrm{PGE}_{2}, \mathrm{TNF}-\alpha, \mathrm{IL}-1 \beta\right)$, and also decrease pain [15].

Comparative histological analysis between 60-day control and LLLT sub-groups show that in both groups it was seen that not only pulp was affected by necrosis but also the periodontal ligament. However, the most important difference between the groups was that the pulpal necrosis of the LLLT sub-group presented well-defined characteristics of a liquefying necrosis that was not observed in the control sub-group.

According to the light microscopy qualitative analysis, the 15-day LLLT sub-group showed an organized histological tissue with nuclei cells when compared to the respective control sub-group. The 30- and 60-day LLLT sub-groups also showed mature histological characteristics with more collagen fibers and small number of necrosis areas when compared to the respective control sub-groups. 
It is important to mention that a longer time elapse to tooth loss and attenuation of symptoms are important aspects to be considered by clinicians to manage the situation and establish a more appropriate treatment planning. These aspects must be observed and analyzed in further studies.

Tooth avulsion lead to a large tissue damage to be overcomed by laser therapy, however, our results open a new perspective of use of LLLT to this purpose. Additionally, different laser parameters need to be tested and clinical studies still need to be performed to evaluate the effects of this therapeutic tool for this particular kind of trauma.

Open Access This article is distributed under the terms of the Creative Commons Attribution Noncommercial License which permits any noncommercial use, distribution, and reproduction in any medium, provided the original author(s) and source are credited.

\section{References}

1. Moura AAM, Prokopowitsch I, Davidowicz H (1994) Etiology and pathogenesis of traumatic dental injuries of patients of the endodontic medical of the University of São Paulo. Endod Dent Traumatol 10(1):45

2. Andreasen JO (1970) Etiology and pathogenesis of traumatic dental injuries. A clinical study of 1,298 cases. Scand J Dent Res 78:329-342

3. Andreasen JO (1992) Atlas of replantation and transplantation of teeth. W.B. Saunders, Philadelphia

4. Andreasen JO, Andreasen FM (1993) Textbook and color atlas of traumatic injuries to the teeth, 3rd edn. Munksgaard Publishers, Copenhagen

5. Blomlöf L, Otteskog P, Hammarström L (1981) Effect of storage in media with different ion strengths and osmolarities on human periodontal ligament cells. Scand J Dent Res 89(2):180-187

6. Chamorro MM, Regan JD, Opperman LA, Kramer PR (2007) Effect of storage media on human periodontal ligament cell apoptosis. Dent Traumatol 24(1):11-16

7. Schwartz O, Andreasen FM, Andreasen JO (2002) Effects of temperature, storage time and media on periodontal and pulpal healing after replantation of incisors in mokeys. Dent Traumatol 18(4):190-195

8. Hiltiz J, Trope M (1991) Vitality of human lip fibroblasts in milk, Hanks balanced salt solution and Viaspan storage media. Dent Traumatol 7(2):69-72
9. Sigalas E, Regan JD, Kramer PR, Witherspoon DE, Opperman LA (2004) Survival of human periodontal ligament cells in media proposed for transport of avulsed teeth. Dent Tarumatol 20(1):2128

10. Pohl Y, Filippi A, Kirschner H (2005) Results after replantation of avulsed permanent teeth. II. Periodontal healing and the role of physiologic storage and antiresoptive-regenerative therapy. Dent Traumatol 21(2):93-101

11. Bakland LK, Andreasen JO (2004) Dental traumatology: essential diagnosis and treatment planning. Endod Topics 7(1):14-34

12. Doyle DL, Dimsha IC, Syduskis RJ (1998) Effect of soaking in Hank's balanced salt solution or milk on PDL cell viability of dry stored human teeth. Dent Traumatol 14(5):221-224

13. Hupp JG, Mesaros SV, Trope IAM (1998) Periodontal ligament vitality and histological healing of teeth stored for extended periods before transplantation. Dent Traumatol 14 (2):79-83

14. Bauss O, Schilke R, Fenske C, Engelke W, Kiliaridis S (2002) Autotransplantation of immature third molars: influence of different splinting methods and fixation periods. Dent Traumatol 18(6):322-328

15. Lopes-Martins RA, Penna SC, Joensen J, Iversen VV, Bjordal JM (2007) Low-level laser therapy [LLLT] in inflammatory and rheumatic diseases: a review of therapeutic mechanisms. Curr Rheumatol Rev 3:147-154

16. Karu T (1999) Primary and secondary mechanisms of action of visible-to-near IR radiation on cells. J Photochem Photobiol 49 (1): $1-17$

17. Walsh LJ (1997) The current status of low level laser therapy in dentistry, Part 1. Soft tissue applications. Aust Dent J 42(4):247-254

18. Walsh LJ (1997) The current status of low level laser therapy in dentistry, Part 2. Hard tissue applications. Aust Dent J 42(5):302306

19. Pretel H, Lizarelli RFZ, Ramalho LTO (2007) Effect of low-level laser therapy on bone repair: histological study in rats. Lasers Surg Med 39:788-796

20. Andreu MIG, Zaldivar CV (1994) Efectos biológicos de la radiacion laser de baja potencia al nível celular. Rev Cubana Estomatol 31(1):18-21

21. Merli LAS, Santos MTBR, Genovese WJ, Faloppa F (2005) Effect of low-intensity laser irradiation on the process of bone repair. Photomed Laser Surg 23:212-215

22. Friedman S, Komorowski R, Maillet W, Nguyen HQ, Torneck CD (1998) Susceptibility of Nd:YAG laser-irradiated root surfaces in replanted teeth to external inflammatory resorption. Endod Dent Traumatol 14(5):225-231

23. Ferreira AN, Silveira L, Genovese WJ, de Araújo VC, Frigo L, de Mesquita RA, Guedes E (2006) Effect of GaAlAs laser on reactional dentinogenesis induction in human teeth. Photomed Laser Surg 24(3):358-365 